\title{
Irmãos de Sangue: um mergulho na República de Weimar
}

Simone Pereira Gonçalves'

Resumo: Apresento aqui a tradução de Blutsbrüder (Irmão de Sangue). A preocupação maior neste trabalho foi encontrar o ritmo mais próximo possível do texto alemão que é leve, dinâmico, marcado por coloquialismos e pela linguagem sóbria da Nova Objetividade [Neue Sachlichkeit], movimento artístico, cultural e literário que surgiu com a Proclamação da República de Weimar, e o fim da Primeira Guerra Mundial.

Palavras-chave: Tradução literária; Nova Objetividade; República de Weimar; Gangues de jovens; Irmãos de sangue.

Seria inexato escrever sobre Blutsbrüder (Irmão de Sangue) e seu autor sem primeiro mencionar quem os descobriu e a relação desta descoberta com uma linha editorial específica. A primeira publicação saiu em 2013 pela editora Metrolit, na época sob a direção de Peter Graf, atual editor da Verlag das kulturelle Gedächtnis (Editora Memória Cultural), criada em 2017 e cujo objetivo é reeditar livros significativos que caíram no esquecimento.

1 Simone Pereira Gonçalves é formada em tradução pela Universidade Humboldt de Berlim e licenciada em filosofia pela UFPR. Traduziu cinco livros do alemão e colabora pela sexta vez com Cadernos de Literatura em Tradução. Participou de diversas oficinas de tradução literária em Berlim e Portugal e foi contemplada com uma bolsa para a Academia Europeia de Tradutores em Straelen [EÜK]. Domiciliada em Berlim há 30 anos, é também tradutora pública e intérprete comercial de português, francês e alemão. Contato: www.transpalavras.com 
Blutsbrïder foi publicado pela primeira vez em 1932, sob o título Jugend auf der Landstraße Berlin (Juventude na estrada de Berlim). O romance urbano de cunho crítico social foi proibido e queimado pelos nazistas. Sobre o autor sabe-se apenas que era jornalista e assistente social. Viveu por volta de 1900 a 1938 e foi provavelmente assassinado pelos nacional-socialistas.

A gangue Irmãos de Sangue compõe-se de jovens sem-teto, de 16 a 19 anos de idade. Os pais morreram na Primeira Guerra Mundial ou não se pode mais contar com eles. Levam uma vida entre as salas de espera da Repartição de Assistência Social, reformatórios - dos quais alguns deles fugiram - e prisões. O território da gangue é a Alexanderplatz, centro de Berlim. Eles vivem de pequenas chantagens, receptação, furtos, falcatruas e prostituição ocasional. O dia a dia deles é marcado pela luta por uma refeição e um lugar para dormir. Quando têm dinheiro, se enchem de pão, salsicha, aguardente e fumam, o que os faz esquecer um pouco o frio e as preocupações. Estão sempre em movimento, à procura de lugares aquecidos como bibliotecas, bares e abrigos para moradores de rua. Sempre com o desejo de normalidade, mas sem os papéis exigidos pela burocracia estatal. Johnny é o cabeça, da gangue, o meganha - como dizem os meninos -, o único que já tem 21 anos, o provedor, uma espécie de figura paterna para os meninos que provoca respeito, carinho e medo. Os protagonistas, Willi e Ludwig entram para a gangue. No início ficam contentes de terem sido aceitos, mas logo percebem que não querem viver na marginalidade, tentam afastar-se e procurar um novo caminho.

\section{A tradução}

A preocupação maior neste trabalho foi encontrar o ritmo mais próximo possível do texto alemão que é leve, dinâmico, marcado por coloquialismos e pela linguagem sóbria da Nova Objetividade [Neue Sachlichkeit], movimento artístico, cultural e literário que surge com a Proclamação da República de Weimar (09/11/1918) e o fim da Primeira Guerra Mundial (11/11/1918). Os literatos dessa fase são muito inovativos e interessados na política, com uma postura crítica aos valores do período conhecido como guilhermino (reinado de Guilherme II): nacionalismo, militarismo, monarquismo, anti-semitismo e valores antidemocratas. A Nova Objetividade se opõe às visões e profecias do período expressionista, preferindo um tom direto, frio e despojado. A realidade é representada com base em fatos econômicos, políticos e sociais e o credo político desses autores é liberal, no sentido de desfesa das liberdades individuais, e de esquerda, no sentido 
de solidariedade com os mais vulneráveis. O romance começa com uma frase longa, composta de vários atributos e construção participial, característica da língua alemã que não corresponde a nenhuma fluidez nas línguas neolatinas, por isso dividi a frase em duas. $\mathrm{O}$ uso de superlativos também é mais frequente em alemão e muitas vezes soa pesado em português, sendo portanto dispensável, como pünkttichst que em português seria algo como pontualissimamente. Traduzi por em ponto. Algumas palavras no original são enfatizadas por caracteres estendidos. Mantive este detalhe da tipografia original que parece ser uma convenção da época. Alterei a pontuação para reduzir repetições de como com sentido exclamativo e acrescentei um ponto de exclamação: Como os meninos estão transformados, como cravam os dentes na ponta da salsicha e trabalham as mandibulas! [Wie verwandelt sind die Jungen. Wie sie die Zähne in die Wurstenden hauen, wie die Kiefer arbeiten]; e então, vamos lá! [Also los] Me permiti também inserir uma aliteração que não tinha no original: sombrio, sinistro e sujo para düster, unbeimlich und unsauber. A fim de manter as mesmas iniciais em português com ressignificação jocosa de uma abreviatura em alemão, traduzi Ewige Hilfe (Eterna Ajuda) por Ajuda Eterna, para não perder a referência religiosa, e Erwerbslosenhilfe por Ajuda Emergencial em vez de auxílio-desemprego. Um regionalismo berlinense Schrippe foi traduzido por um termo genérico, pãozinho, com o propósito de evitar um falso regionalismo; traduzi por bar os diferentes termos em alemão[Kneipe, Lokal] e [Klause] por botequim, por me soar mais tradicional. A expressão Bulle [touro], bastante comum e pejorativa para se referir a um policial na Alemanha, foi traduzida por meganha, por me parecer mais conhecida e não estar associada a algo muito específico como macaco ao cangaço ou praça à polícia militar.

A tradução Irmãos de Sangue é uma tentativa de levar o espírito desta obra à cultura de chegada. Nesta tarefa procuro me aproximar da teoria ilusionista, proposta por Jirî Levý, a qual relaciona a arte de traduzir às artes cênicas do teatro clássico. Como o ator que ao interpretar um papel simula uma realidade, produzindo uma ilusão no espectador, a tradução ilusionista visa provocar a ilusão no leitor de se ler o original. De fato, trata-se de um texto original, escrito em língua portuguesa, mas com a peculiaridade de não ser completamente autônomo, de ter sua existência fundamentada no texto de partida. Desta dependência surge o desafio de transpor para a cultura alvo uma realidade social, histórica e institucional tão diferente dela, sem provocar estranhamentos que desqualifiquem o texto, como a falta de fluência e até mesmo de sentido. Mas também sem domesticá-lo, sem privar o leitor de conhecer uma realidade diferente e mergulhar na República de Weimar ao ler Irmãos de Sangue. 
Irmãos de sangue

1. A gangue de jovens

Irmãos de Sangue e a Ajuda Eterna.

Jonny, o meganha da gangue.

Quarenta e cinco

pãezinhos

e duas salsichas.

"Tira, Branco, tira."

Elementos minúsculos formam uma fila de pessoas cansadas que serpenteia o longo pátio industrial e dois andares. Oito meninos da gangue Irmãos de Sangue esperam, como centena deles, finalmente poder sair do terrível frio úmido e entrar nas salas de espera quentinhas. Três, quatro minutos ainda de espera e às oito em ponto abrirão a pesada porta de ferro no segundo andar. A Repartição do Bem-Estar Social do distrito de Mitte na Chausseestrasse deu o primeiro solavanco na marcha de seu complicado funcionamento burocrático. O solavanco se reproduz múltiplas vezes de forma sinuosa pela fila. As pessoas avançam, os pés impacientes, nas mãos seguram a papelada necessária. De forma atenciosa e oficial foi entregue uma guia impressa, contendo uma lista sem fim de papéis necessários e os vinte e quatro cantos da cidade onde se podem obtê-los.

A fila já alcançou a enorme sala de espera da caixa. Desta fila formam-se imediatamente duas filas pequenas, organizadas com precisão militar. Uma fila espera pacientemente até a voz rouca do faz-tudo da repartição, Paule, recolher os cartões para carimbar e preparar os pagamentos. A filinha número dois serpenteia até chegar ao balcão de informações para receber um cartãozinho com um número, depois de respondidas as perguntas sobre o de onde e o para onde. Dali cada um voa para outras duas salas para, com uma paciência de Jó, esperar a chamada de seu número diante das portas dos senhores despachantes. A paciência de Jó tem que durar bem umas cinco, seis horas. Os oito meninos da gangue não se juntam a nenhuma das duas filinhas, mas chispam para a Ajuda Eterna. Talvez ainda se consiga um banco para sentar.

Sala de Espera da Ajuda Eterna. Nos escritórios são feitos os requerimentos de concessão da Ajuda Emergencial. Com uma irreverência mordaz, a abreviatura oficial "A. E." foi ressignificada como Ajuda Eterna. Apenas meia hora depois de terem aberto, a ampla sala já está lotada. Os poucos bancos estão repletos até o último cantinho. Os que não conseguiram mais um lugar para sentar, ficam de pé no corredor ou se encostam nas duas paredes longitudinais com horríveis manchas 
pretas e ensebadas das milhares costas humanas que nelas se encostaram. Uma luz indizivelmente inconsolável do dia cinzento mistura-se com o reflexo fraco da lâmpada elétrica e cria uma luz difusa em que o rosto dos que esperam parece ainda mais miserável e faminto. Atrás das paredes transversais ficam os escritórios, claros e limpos. Embora não tenham esquecido de colocar portas, fizeram nas paredes uma abertura extra e quadrada para a cabeça grande de servidor de faixa salarial baixa. Diretamente ao lado da porta. A fim de evitar qualquer contato desnecessário com a plebe que espera, os servidores públicos chamam não pela porta. Não: a portinhola é escancarada, finamente emoldurada aparece a cabeça de homem e berra um número. Em seguida, a portinhola fecha batendo com força. O número chamado - só no escritório se descobrirá que é Gustav Meyer ou Frieda Abrameit - vai trotando pela porta do escritório ao lado da portinhola. A cada chamada de número, um levantar de cabeças dos que esperam. Às vezes, acontece de as portinholas se abrirem ao mesmo tempo nas duas paredes e aí, vapt-vupt: ergue a cabeça, vira a cabeça para trás.

Os oito meninos conseguiram pegar um banco inteiro, não estão nem aí para a chamada e dormem, tiram um cochilo. Passaram a noite inteira, gelada e sem fim, na rua. Com frequência, como sem-teto. Sempre saltitando, sempre em movimento. Com um clima daqueles, descansar era fora de questão. Lama de neve durante dias, de vez em quando uma chuva fina e forte, tudo requintadamente misturado com um vento que deixava os meninos batendo queixo pelo frio penetrante, feito patos grasnando. Oito meninos, de dezesseis a dezenove anos de idade. Alguns fugiram do reformatório. Dois deles ainda têm pais em algum lugar na Alemanha. Um ou outro ainda tem pai ou mãe. Nasceram ou passaram a adolescência durante a Guerra ou o Pós-Guerra. Ao tentarem dar os primeiros passinhos de pernas tortas, já se encontravam entregues a si próprios. O pai estava na guerra ou já na lista dos desaparecidos. A mãe fabricando granadas ou expectorando centigramas do catarro de seus pulmões nas fábricas de pólvora e explosivos. As crianças de barriguinha proeminente por conta da alimentação à base de couve-nabo - sequer de batata - espreitavam nos pátios e nas ruas à procura de algo para comer. Assim que cresciam, iam em matilhas, roubar para encher a barriga. Pequenos animais predadores. Malignos.

O Ludwig de Dortmund acordou com a chamada de um número. Agora está ali sentado, as pernas esticadas, os punhos cerrados nos bolsos, no canto da boca uma piteira vazia. No rosto jovem e magro de fome, os olhos castanhos e ágeis miram interessados a entrada da sala. Os camaradas dormem, a cabeça inclinada para frente, o corpo caído ou encostado no vizinho, exaustos. Jonny, o líder 
deles, o meganha, os convocou aqui às nove horas. Ele queria, como de costume, arranjar dinheiro. Como consegue, isso ele não revela. Ontem à noite por volta das dez, despediu-se dos camaradas. Ludwig vê Jonny entrando na sala e acena agitado “Aqui, Jonny, aqui!". Jonny é um jovem de vinte e um anos. O queixo marcante e o maxilar saliente dão um aspecto meio brutal, ao menos atestam força de vontade. Sua fala é inteligente e bem colocada, quase sem dialeto e prova que intectualmente supera todos da gangue. A superioridade em força física é uma obviedade, senão não seria meganha. "Bom dia, Ludwig!" e passa-lhe um maço de cigarro. Saudoso, ávido, Ludwig se serve e sorve com volúpia a fumaça da qual havia se privado. Os camaradas ainda estão dormindo. Ludwig dá uma tragada profunda e sopra a fumaça nos meninos. Eles engolem, tossem e acordam. Nada os teria acordado mais rápido do que isso. Cigarro? Jonny, oil Rapidamente cada um se serve. E agora também se sabe que Jonny tem dinheiro, que finalmente vão poder comer e então, vamos lá! Como sempre, eles andam separados, em três grupos. Nove meninos juntos chamam a atenção, provocam suspeita. Da Chausseestrasse entram na Invalidenstrasse. Aqui comprarão o café da manhã. Cinquenta pãezinhos em três sacos robustos e uma salsicha inteira condimentada com cebola. Vai dar para os nove.

Rosenthaler Platz, Mulackstrasse e depois para a Rückerstrasse. Entram no bar preferido de todas as gangues da Alexanderplatz, o Rückerklause. Pela janela já se vê os bolinhos de batata sendo preparados laboriosamente. A nuvem de fumaça engordurada se espalha pelos cantos mais recônditos do bar sombrio, sinistro e sujo. Apesar de ser muito cedo, o botequim está cheio. Ele é mais do que simplesmente um bar. É uma espécie de lar para quem não o têm. Barulho da música do alto-falante, barulho dos fregueses. Ninguém se incomoda com o bufê pouco apetitoso, com as mesas molhadas de cerveja e a sujeira preta das paredes riscadas. A gangue se senta num canto à direita da entrada. O garçom traz um caldo medonho, mas pelo menos está quente. E então, ao ataque: detonar os pãezinhos e as salsichas, sem muita conversa. Só ruídos graves, quase animalescos, grunhidos pelos quais o estômago manifesta sua saciedade. Como os meninos estão transformados, como cravam os dentes na ponta da salsicha e trabalham as mandíbulas! Como se entreolham e com o olhar dizem: "Cara, isso é bom demais, comer e ver que ainda tem mais...". E os outros olhares, gratos, orgulhosos de reconhecimento, por Jonny ter novamente comprado para todos.

Atrás, num cantinho, um dos meninos ainda na flor da idade está sentado no colo de um cliente meio embriagado. De frente para esse canto, dois camaradas andam de um lado para o outro e chamam encorajando o companheiro: "Tira, Branco, tira!". Tira a carteira do teu cliente e passa pra gente... 
Entre dois meninos da gangue, encostada na mesa diante do bufê, uma menina de quinze, dezesseis anos. A malandra colocou nos ombros a jaqueta de um dos meninos que estava com calor, boina de aba na cabeça, bebe uma aguardente atrás da outra com os dois meganhas de jaqueta de couro. O rosto de uma palidez doentia, com veias azuladas nas têmporas, transfigura-se numa expressão de repugnância, mas a pequena mão suja pega de novo o copo de aguardente, dando um sinal a um dos meninos de jaqueta de couro. A boca da menina se abre: quase sem dentes, restam uns cacos pretos. Certamente ainda não tem nem dezesseis anos...

Atrás do balcão, o dono está atento. Com um bom terno azul e um colarinho branquíssimo, o único em todo o bar. A música estrondosa e incessante. É um entra e sai sem parar. Tudo gente jovem, muito jovem. Muitos vão de mochila com algum tipo de pacote. A seguir vão para a antessala, para o banheiro imundo. Conversa rápida, desembrulhar, empacotar. O dinheiro troca de dono. No balcão é tomar aguardente e cair fora. Não são raras as batidas policiais.

A menina, completamente bêbada, vai de mesa em mesa trançando as pernas e se oferecendo. A Friedel está se exibindo de novo, dizem e não se sentem mais tocados pela triste cena de uma menina bêbada mostrando seu exíguo charme. Rückerklause, uma espécie de lar para quem não tem. A fome permanente dos meninos devastou a mesa, detonando os pãezinhos e salsichas e, ainda por cima, dois bolinhos de batata para cada um. Recostam-se aconchegados, fumam um cigarro, bebem um gole de cerveja e zunzunam a melodia do alto-falante: “... Meu tesouro, meu coração não é um eterno ancoradouro...”. Estão saciados, o bar quentinho, bate o cansaço e debruçam-se na mesa. Só Jonny se mantém acordado, e fuma sem parar. Paga toda a conta, depois conta o dinheiro. Oito marcos ainda. Onde vão dormir esta noite? Os mais baratos albergues em massa cobram cinquenta pfennig pelo uso de um colchão miserável cheio de percevejos. Dá quatro marcos e cinquenta pfennig, mal sobra para o dia seguinte. Jonny fica matutando sobre uma possibilidade mais barata de pernoite. Os meninos podem continuar dormindo. O garçom deverá avisá-los que Jonny vai esperá-los às oito horas no Schmidt. 
Blutsbrüder

\author{
1. Die Jugendlichen-Clique \\ BLUTSBRÜDER und die EWIGE HILFE. \\ - Jonny, Cliquenbulle. - \\ Fünfundvierzig \\ Schrippen \\ und zwei Würste. - \\ "Zieh, Schimmel, zieh."
}

Winzige Glieder einer sich durch den langen Industriehof und zwei Etagen windenden müden Menschenschlange stehen die acht Jungen der Clique Blutsbrüder und warten gleich den hundert anderen darauf, endlich aus der furchtbaren Naßkälte in die warmen Wartesäle gelassen zu werden. Drei, vier Minuten wird es noch dauern. Dann, acht Uhr pünktlichst, wird in der zweiten Etage die schwere Eisentür geöffnet. Das Bezirkswohlfahrtsamt Berlin-Mitte in der Chausseestraße hat den ersten Ruck zur Ingangsetzung seines bürokratisch komplizierten Betriebes getan. Der Ruck pflanzt sich vielfach gewunden in der Menschenschlange fort. Die Glieder rücken auf, scharren mit den Füssen, halten in den Händen die unzähligen notwendigen Papiere. Zuvorkommend hat man amtlicherseits einen gedruckten Leitfaden herausgegeben, der in endloser Kolonne die nötigen Papiere aufzählt und an welchen vierundzwanzig Stadtzipfeln man solche ausgestellt bekommt.

Die Schlange hat bereits den riesigen Kassenwarteraum erreicht. Aus der Schlange bilden sich flugs zwei Schlänglein, militärisch exakt organisiert. Das eine Schlänglein wartet geduldig, bis das heisere Amtsfaktotum Paule ihm die Stempelkarten zur Vorbereitung der Auszahlungen abnimmt. Schlänglein Nummer zwei windet sich vor den Auskunftsschalter, um hier nach Beantwortung der Woher- und Wo-hinfragen eine Pappnummer zu erhalten. Dann stieben die einzelnen Glieder in zwei andere Säle vor die Türen der Herren Expedienten, um hier lammsgeduldig den Aufruf der Nummer zu erwarten. Die Lammsgeduld muß gut und gern fünf, sechs Stunden vorhalten. Die acht Cliquenjungen schließen sich weder dem einen noch dem anderen Schlänglein an, sondern flitzen schleunigst in die E w i g e Hilfe. Vielleicht ist noch eine Bank zu ergattern.

Wartesaal der Ewige Hilfe In den dazugehörigen Büros werden die Anträge auf Gewährung der Erwerbslosenhilfe gestellt. Die amtliche Abkürzung „E.H.“ hat eine bissige Schnoddrigkeit in Ewige Hilfe umgedeutet. Bereits jetzt, eine halbe Stunde nach Öffnung, ist der große Saal überfüllt. Die wenigen Bänke sind 
bis auf das letzte Plätzchen besetzt. Die keinen Sitzplatz mehr fanden, stehen im Gang herum oder lehnen sich an die beiden Längswände, die von abertausenden anlehnenden Menschenrücken scheußliche, fettigschwarze Flecken bekommen haben. Ein unsäglich trostloses Licht des grauen Tages mischt sich mit dem Schein der schwachen elektrischen Birne und schafft so ein Zwitterlicht, in dem die Gesichter der Wartenden noch elender, noch verhungerter erscheinen. Hinter den beiden Querwänden sind die hellen sauberen Büroräume. Obwohl man in den Wänden auch Türen nicht vergessen hat, hat man noch extra je ein viereckiges Loch - Größe Beamtenkopf der unteren Gehaltstufen - in die Wände gestemmt. Unmittelbar neben den Türen. Um jede unnötige Berührung mit dem wartenden Plebs zu vermeiden, rufen die Beamten die Nummern nicht durch die Türen. Nein: die Klappe wird aufgerissen, fein gerahmt erscheint ein Mannskopf und brüllt die Nummer aus.

Dann fliegt die Klappe schleunigst wieder zu. Die aufgerufene Nummer erst im Büro stellt sich heraus, daß sie Meyer Gustav oder Abrameit, Frieda heißt - trottet durch die Tür neben der Klappe ins Büro. Bei jedem Aufruf der Nummer fliegen die Köpfe der Wartenden hoch. Zuweilen kommt es vor, daß sich an den beiden Wänden zugleich die Klappen öffnen. Dann fliegen - ruck - alle Köpfe hoch, - zuck - alle Köpfe nach hinten.

Die acht Jungen haben noch eine ganze Bank ergattern können, kümmern sich um keinen Aufruf und schlafen, dösen vor sich hin. Sie waren die ganze, endlose Winternacht auf der Straße. Wie schon so häufig: obdachlos. Immer getippelt, immer in Bewegung. Ausruhen war nicht bei dem Wetter. Tagealter Schneematsch, ab und zu ein dünner Strippenregen, alles fein gemixt durch einen Wind, der die Münder der Jungen vor durchdringender Kälte wie Entenschnäbel schnattern ließ. Acht Jungens, sechzehn bis neunzehn Jahre alt. Einige sind aus der Fürsorgeanstalt geflüchtet. Zwei haben noch Eltern irgendwo in Deutschland. Der eine oder andere noch Vater oder Mutter. Ihre Geburt, ihre früheste Jugend fiel in die Zeit des Krieges und Nachkrieges. Schon als sie ihre ersten o-beinigen Gehversuche machten, waren sie sich selbst überlassen. Vater war im Krieg oder stand bereits auf der Verlustliste. Und Mutter drehte Granaten oder hustete ihre Lungen in den Pulver- und Sprengstoffabriken zentigrammweise aus. Die kohlrübenbauchigen Kinder - nicht einmal mehr kartoffelbäuchig waren sie - luchsten in Höfen und auf den Straßen nach Eßbarem. Wuchsen sie heran, gingen sie rudelweise auf Raub aus. Raub, um die Bäuche zu füllen. Bösartige, kleine Raubtiere.

Der Dortmunder Ludwig ist beim Ruf einer Nummer wach geworden. Jetzt sitzt er da, Beine von sich gestreckt, Fäuste in den Taschen, im Mundwinkel eine leere Zigarettenspitze. Das schmale verhungerte Jungensgesicht mit den flinken 
braunen Augen guckt interessiert auf den Saaleingang. Die Kameraden schlafen, vornübergebeugt, zusammengesunken oder sich kraftlos an den Nachbarn lehnend. Jonny, ihr Anführer, ihr Bu11 e, hat sie zu neun Uhr hierherbestellt. Er wollte, wie so häufig, Geld auftreiben. Wie er das macht, verrät er nicht. Gestern abend gegen zehn Uhr verabschiedete er sich von den Kameraden. - Ludwig sieht Jonny in den Saal kommen und winkt aufgeregt. „Hier, Jonny, hier!“ Jonny ist ein junger Mensch von einundzwanzig Jahren. Das starke Kinn, die hervorspringenden Backenknochen wirken etwas brutal, zeugen wenigstens von Willenskraft. Seine Rede ist klug und wohlgesetzt, fast dialektfrei und beweist, daß er jeden der Clique geistig überragt. Überlegene Körperkraft ist selbstverständlich, sonst wäre er nicht Bulle. „Morgen, Ludwig!“ Er reicht ihm eine große Schachtel Zigaretten. Sehnsüchtig, gierig bedient Ludwig sich und kaut wollüstig den entbehrten Rauch. Die Kameraden schlafen noch immer. Ludwig nimmt einen tiefen Zug und pafft die Jungens an. Sie schlucken, husten, wachen auf. Kein anderes Mittel hätte sie schneller wecken können. Zigaretten? Jonny, hallo!

Schnell bedient sich jeder. Und jetzt weiß man auch, daß Jonny Geld hat, daß sie endlich mal wieder zu essen bekommen. Also los. Wie immer, gehen sie getrennt, in drei Gruppen. Neun Jungens zusammen erregt unliebsames Aufsehen. Sie biegen von der Chaussee- in die Invalidenstraße ein. Hier wird das Frühstück eingekauft. Fünfundvierzig Schrippen in drei mächtigen Tüten und zwei ganze Zwiebelleberwürste. Das wird reichen für neun Mann.

Rosenthaler Platz, Mulackstraße, dann in die Rückerstraße. Hinein in die Stammkneipe aller Cliquen rund um den Alexanderplatz, in die Rückerklause. Im Schaufenster werden schon fleißig Kartoffelpuffer gebacken. Die fettigen Rauchschwaden ziehen in entfernteste Winkel des düsteren, unheimlichen und unsauberen Lokals. Trotz der frühen Stunde ist die Klause voller Gäste. Sie ist mehr als bloße Kneipe. Sie ist eine Art Zu Hause für den, der es nicht hat. Lärmende Lautsprechermusik, lärmende Gäste. Die Unappetitlichkeit des Büfetts, der biernassen Tische, der schmutzschwarzen bekritzelten Wände stört niemanden. Rechts vom Eingang in einer Ecke nimmt die Clique Platz. Der Kellner bringt schauderhafte, aber wenigstens heiße Bouillon. Dann wird die Vertilgung der Schrippen und der Würste in Angriff genommen. Gesprochen wird nicht viel dabei. Nur dunkle, fast tierische Laute, Gegrunze, mit dem der Magen seine Befriedigung äußert. Wie verwandelt sind die Jungen. Wie sie die Zähne in die Wurstenden hauen, wie die Kiefer arbeiten. Wie sie einander ansehen und sich mit Blicken sagen: „Junge, Junge, ist das gut, so zu essen und zu sehen, daß noch mehr da ist..." Und die anderen Blicke, die dankbaren, die stolzen, die Jonny gelten, der mal wieder für alle angeschafft hat. 
Hinten in einer der Nischen sitzt ein blutjunger Cliquenbursche auf dem Schoß eines benebelten Freiers. Zwei Kameraden des Burschen spazieren vor der Nische auf und ab und rufen ihrem Kumpan ein aufmunterndes „Zieh, Schimmel, zieh!“ zu. Zieh deinem Freier die Brieftasche und steck sie uns zu ...

Zwischen zwei Cliquenbullen am Stehtisch vor dem Büfett lehnt ein Mädchen, ein Kind von fünfzehn, sechzehn Jahren. Keß hat es sich das Jackett eines Burschen, dem zu heiß geworden war, übergezogen, die Ballonmütze aufgestülpt und trinkt mit den beiden lederjackenen Bullen einen Schnaps nach dem anderen. Das krankhaft blasse Gesicht mit dem blauen Schläfengeäder verzieht sich zu einem Ausdruck des Ekels, dann aber greift die kleine, schmutzige Hand wieder nach dem Schnapsglas, um einer Lederjacke Bescheid zu tun. Der Mund des Mädchens öffnet sich: fast zahnlos, nur vereinzelte schwarze Reste. Und das Mädchen ist bestimmt noch keine sechzehn Jahre alt...

Hinter der Theke steht aufmerksam der Wirt. In einem guten blauen Anzug und blütenweißem Kragen, dem einzigen im ganzen Lokal. Ununterbrochen dröhnt Musik. Ununterbrochen kommt und geht es in dem Lokal. Alles junge, jüngste Menschen. Viele kommen mit Rucksäcken, irgendwelchen Paketen. Dann geht es in den Vorraum zu der grauenhaft verschmutzten Toilette. Kurzes Gespräch, Auswickeln, Einpacken. Geld wechselt seinen Besitzer. An der Theke wird ein Schnaps getrunken. Weg. Polizeiliche Razzien sind nichts Seltenes.

Das Mädchen ist jetzt sinnlos betrunken, torkelt von Tisch zu Tisch und bietet sich an. Friedel gibt mal wieder an, sagt man und ist nicht weiter von der traurigen Szene eines betrunkenen Kindes, das seine mageren Reize zeigt, berührt. Rückerklause, eine Art Zu Hause für den, der es nicht hat. Der ewige Hunger der Jungen hat Schrippen und Würste und auch noch je zwei Kartoffelpuffer restlos vom Tisch gefegt. Wohlig lehnen sie sich zurück, ziehen an der Zigarette, trinken einen Schluck Bier und summen die Lautsprechermelodie mit: „... Auf die Dauer, lieber Schatz, ist mein Herz kein Ankerplatz ... "Gesättigt sind sie, im Lokal ist es warm. Müdigkeit kommt auf. Die Köpfe sinken auf die Tischplatte. Nur Jonny sitzt wach und raucht und raucht. Er bezahlt die Gesamtzeche. Dann zählt er sein Geld. Noch runde acht Mark. Wo werden sie heute nacht schlafen? Die billigste Massenherberge nimmt für die Benutzung einer elenden Wanzenmatratze fünfzig Pfennig. Macht vier Mark fünfzig Pfennig, dann reicht es kaum noch für den morgigen Tag. Jonny grübelt nach einer billigeren Schlafgelegenheit. Die Jungens sollen nur weiterschlafen. Der Kellner soll ihnen sagen, daß Jonny sie abends acht Uhr bei Schmidt erwartet. 


\section{Referências bibliográficas}

HAFFNER, Ernst. Blutsbrüder. Berlin: Aufbau Verlag. 2015.

LEVÝ, Jirî. Die literarische Übersetzung, Theorie einer Kunstgattung. Frankfurt am Main: Athenäum Verlag. 1969. 